\title{
The Unrelenting Progressive Corporate Capture of Food and Nutrition Governance Spaces: A Reassessment of the Challenges
}

\author{
Radha Holla \\ Claudio Schuftan
}

In the current decade, nutrition faces two renewed challenges: corporate control over food and nutrition, and the absence of a focus on the social determinants of nutrition (SDN). Even as neoliberal policies have led to an increase in the real numbers of those rendered poor, the wealth of the few has increased astronomically creating an ever wider and deeper disparity between those rendered rich and those rendered poor not just between countries, but also within nations. The inequitable access to good nutrition this brings about has intensified existing rates of undernutrition and has pushed obesity rates to unprecedented levels. This, in turn, has led to an increase in diseases like hypertension, cardiovascular diseases and cancers. Thus an expansion of nutritional diseases accompanies the expansion of control huge corporations exert over markets for food and agricultural goods. This in turn, day-in-day-out, increases their power to intervene in global and national nutritional policy making.

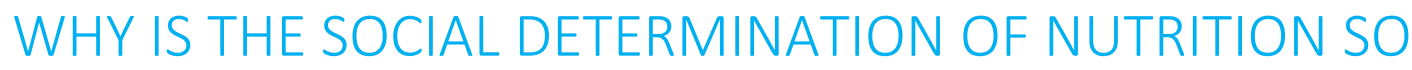

\section{IMPORTANT?}

The social determinants of nutrition correspond to the conditions under which people are born, grow, live, work and age, including the nutrition services available (or not) to them. These circumstances are shaped by the distribution of wealth, power and resources at global, national and local levels, which in turn, beyond doubt, influence policy choices. Neoliberal economic policies have globally led to wealth and power being concentrated in fewer hands and a concurrent increase in poverty within and among nations. Nutrition policy making within the human rights framework requires that the SDN, including their political determinants, are placed at the centre of such policies both at the global and the national level. However, the past decade has seen a persistent ignoring of the SDN, as well as a concentration of the corporate control over food and nutrition.

While these concerns are purposely not mentioned by the private sector that focuses almost exclusively on increasing profits, governments and international organisations such as WHO are also not emphasizing them enough. This neglect has been primarily due to the large presence of 
corporate funding in the budgets of these institutions that, even if indirectly, influence the global governance of nutrition.

\section{$\underline{B o x} 1$}

The former UN Special Rapporteur on the Right to Food, Olivier De Schutter, spoke in favour of "addressing the full range of factors causing malnutrition, rather than narrowly focusing on initiatives that address just the specific needs of a child's development [...]. [I]nterventions [...] targeting pregnant or lactating women and children under two years old, while vital, do not substitute for addressing the structural causes of undernutrition [...]. The violations of women's rights, gender inequality and the lack of women's empowerment are another major factor explaining poor nutritional outcomes. [...]. Nutrition interventions should be but one part of broader-based strategies for the realization of the right to adequate food. [...]”.

The Special Rapporteur [also] saw "no reason why the promotion of foods that are known to have detrimental health impacts should be allowed to continue unimpeded: these products reduce the life expectancy, in particular, of the poorest segment of the population who are also the least nutritionally literate [....] [A]n international code of conduct regulating marketing food and beverages in support of national efforts might be desirable in order to take into account the international nature of commercial promotion of energy-dense, micronutrient-poor foods and beverages. [...]”.

It is high time, he thought, "to recognize the real tension that exists between a strategy that promotes processed foods, enriched with nutrients to the point that diets become medicalized, and a strategy that promotes local and regional food systems, as well as a shift towards foods that are less heavily processed and thus more nutritious.”

\section{CORPORATE CONTROL OVER FOOD AND NUTRITION}

Corporate control over food infiltrates the health and nutrition system at all levels. It starts with the creation of evidence.

\section{Corporate control over evidence}

In the nutrition sector, research is often conducted or sponsored by food and beverage companies; this may influence the results and/or conclusions of the research (Bes-Rastrollo et al., 2013; Katzmarzyk et al., 2016; Siri-Tarino et al., 2010), as researchers can be pressured to change the design of the study, the methodology, the results, or which results are reported and how (Fanelli, 2009). For instance, the International Life Sciences Institute (ILSI), that has branches in several countries, claims that its mission is "to provide science that improves human health and well-being and safeguards the environment. For over 40 years, ILSI has specialized in convening scientists from the public and private sectors to collaborate in a neutral forum on 
scientific topics of mutual interest.” (https://ilsi.org/) ILSI's members comprise of leading food and beverages companies, agrichemical and agro-processing and pharmaceutical companies.

Often, professors of reputed universities and institutions are funded by the food and beverages industry to conduct research that then carries the weight of academic authority and gets included in the scientific literature (Mars Centre for Cocoa Health Science, 2017; O’Connor, 2015). Companies such as Nestle, BASF, PepsiCo, Hinsdale Farms, American Vineyard Foundation, Iowa Soybean Association, United Soybean Board, American Cattlemen's Association, and National Pork Board are among those who fund the food science departments and chairs of various universities. Government research institutes are also increasingly being funded by the food and pharmaceutical industry (Coca Cola website, 2019; CDC Foundation, 2018). Such funding raises serious questions on the neutrality of research by public-sector organisations that accept funds from the industry.

\section{Corporate presence in global governance systems}

The private sector, international philanthropies, and some international NGOs have gained unprecedented influence in global governance while States have seen a clear decline in their influence. The ostensible explanation given for the close interaction with the corporate and private sector is the 'scarcity' of public funding. However, this scarcity applies biasedly to funding development initiatives in the public space, as sufficient public funds are often made available for corporate bailouts. One key result of this increased influence has been pressure to form private-public partnerships (PPPs), now perhaps the number one strategy to manage the health and nutritional needs of the world's population (Fanzo et al., 2020). To put it simply, such partnerships represent a rejection of government-led approaches to manage malnutrition including managing markets, and instead prioritize market-led strategies that limit government's role and responsibility for public health nutrition.

In recent years, the United Nations has been pressured to promote PPPs (more often than not contracted with for-profit entities). These PPPs are considered by many to be a necessary and ideal instrument to fund development work. However, a deeper analysis reveals the multiple (sometimes contradictory) agendas and conflicting interests involved. An example of such a PPP is the SUN Initiative (now merged with the formerly UN-mandated and uncompromised UN Standing Committee on Nutrition (SCN) to form “UN Nutrition”), analysed below.

PPPs have further reinforced selective programs by focusing on non-sustainable technocentric and market-based solutions to single issues while not addressing the social determinants of health and nutrition. PPPs have been shown to be incapable of promoting and supporting horizontally-integrated sector-wide approaches that have an explicit commitment to strengthening participatory local service delivery systems and to respond to locally determined people-felt needs. The necessity of building new alliances with public interest civil society and people's organizations, as well as with social movements in pursuing a truly right-to-nutritioncentred roadmap reasserts the central place democratic participation must have in decisionmaking in the provision of all social services. Because the partner (supposedly) supplying the 
financing in these projects tends to have a disproportionate amount of power in decision making, democratic participation is not and cannot be guaranteed in the PPP model. (Note that the private partner not infrequently demands the state funds PPP activities over which the commercial partner nevertheless has an interest, perhaps providing only business "expertise").

Another basic flaw is that PPPs often focus on piecemeal technical and market-driven solutions that provide clear benefits for participating corporations, but questionable benefits for target populations, while ignoring the social roots of their problems, as is clearly evident in the SUN Initiative.

\section{The World Health Organization}

Though WHO is a member-state-run organization, its funding from the wealthier member countries began to decline starting in the early 80 s, as neoliberal policies began to be implemented globally (Reddy et al., 2018). As the second step in the neoliberal strategy to shrink public and expand private control over global policy making, member states then began to express concern over WHOs limited resources and supposed inability to meet its commitments. This, as intended, then has led to a growing WHO dependence on the private sector and philanthropic organizations for funds, shifting its priorities, now often donor-driven and in conflict with the priorities of member-states and even with its own charter. Today, the Gates Foundation (BMGF) provides about 15\% of the overall WHO budget. This allows the foundation to have an inordinate backstage presence in WHO's decision-making process. For example, WHO allocated more than 17 percent of its 2014-15 program budget for polio eradication, which was not a priority for most member states, but was a priority of Gates (Yanzhong Huang, 2016).

Besides the BMGF, WHO also now counts on private sector funding for many of its other public health and nutrition programs, engaging with various global and national corporations.

\section{The SUN initiative and the Global Alliance for Improved Nutrition (GAIN)}

The SUN initiative claims to be a "movement" promoting "a renewed effort to eliminate malnutrition, based on the principle that everyone has a right to food and good nutrition.... by bringing different groups of people together--governments, civil society, the United Nations, donors, businesses and scientists." (SUN brochure) An important funder is the BMGF.

The SUN Roadmap and Strategy (2016-2020) focusses on enabling agribusinesses within countries to increase their control over food and agriculture through support systems such as the SUN Business Network (SBN), Civil Society Networks and the SUN Donor Network. For instance, the SBN works with partners from government, civil society, the UN and donors to find the solutions to end malnutrition through business, markets and people by building profitable local business models that can be scaled up. The network currently has 23 members which include GAIN (the largely food industry-funded Global Alliance for Improved Nutrition), DSM, Mars, Pepsico, Ajinomoto, Kellogg, Cargill and Unilever, many of which have contributed significantly to the increase in malnutrition, particularly obesity. The innovations promoted by these corporations include manufacturing ultra-processed foods for children, ready-to-use 
therapeutic and supplementary food products, including wafer snacks, to treat malnutrition in children, strengthening industrial food supply chains, and so on. Interestingly, many of the SBN partners in member countries are TNCs, often their own subsidiaries. For example, the 36 partnerships of SBN members in Indonesia include Ajinomoto Indonesia, BASF Indonesia, Bayer Indonesia, Cargill Indonesia, DSM Nutritional Products Indonesia, Heinz ABC Indonesia, Mondelez Indonesia, Philips Indonesia, Reckitt Benckiser Indonesia and Unilever Indonesia. SBN also partners with local banks to provide these businesses easy access to financial resources.

Some of the partnerships in SUN are supported by GAIN, a PPP itself. It was launched at the 2002 special session of the General Assembly on Children. GAIN claims its mission to be "to advance nutrition outcomes by improving the consumption of nutritious and safe food for all people, especially the most vulnerable to malnutrition”. Its Partnership Council, that advises the Board and the Strategic Management Team, is chaired by DSM and has representatives of WHO, international NGOs, funding organisations and the agri-food industry as members. Many of these members also have decision-making powers in SUN. While GAIN initially invested in largescale staple food fortification, it is currently also involved in assisting companies in producing food products for children and adolescents, and creating markets for the same. GAIN partners with corporations such as Unilever, Ajinomoto, Britannia, Cargill, The Coca Cola Company, DSM, Danone, MARS, PepsiCo, Kraft Foods, and Bel, many of which have been indicted by people's organizations with human rights violations, including violation of international laws and codes and thus contributing to malnutrition. In GAIN, the role of the governments is to buy these enriched products year after year to feed their malnourished. In doing so, they spend their limited health and nutrition budget on products, rather than investing in long-term solutions like diversification of agriculture and diets, family farms, or in tackling the SDN. For instance, readyto-use therapeutic foods (RUTFs are a single shot solution being promoted not just for the treatment of acute, severe malnutrition, but also for its prevention)), fortificants and infant formulas are too often used inappropriately and can increase health and nutritional problems, both for over- and under-nutrition. Often, these ultra-processed products replace whole foods. The marketing and consumption of these substitutes or of related products, in place of a freshly cooked nutritionally balanced meal, contributes to major public health problems.

Good nutrition is about accessing a healthy diet that includes a wide range of fruits and vegetables which, in most cases, are more expensive per calorie than ultra-processed foods rich in oils, salt, sugars and fats, ingredients for which the food industry has often secured government subsidies. Any society where a healthy diet is more expensive than an unhealthy diet is a society that must mend its food system. This is even more imperative where the poorest are too poor to feed themselves in a manner not detrimental to their health.

The SUN Roadmap, that details the means by which national, regional and international actors will work together to establish and pursue efforts to make nutrition interventions more largescale and effective in countries with a high burden of malnutrition, gives little importance to 
human rights except to token words like 'it should be rights-based'. Instead, it has prioritized mostly technical interventions, all of which are 'top-down'. One cannot find anything substantial related to the right to nutrition in the SUN Roadmap. SUN ignores the fact that there are claim holders and duty bearers involved in social interactions, and that it is only their direct engagement that will move the process of realizing this right forward.

Moreover, the SUN initiative is completely silent on the social determination of nutrition. Its proposed 'pro-poor' orientation has simply indicated who are the targets for its technical interventions, never addressing inequitable wealth distribution, a lack of access to food, or poverty; it does not spell out methods for disparity reduction. In the absence of any consideration of the SDN, this 'nutrition with a human face' victimizes people rendered poor as if they are responsible for their malnutrition and then throws them a crumb of bread.

People experience poverty and the violation of their right to nutrition differently, according to their gender, age, caste, class, religion and ethnicity. For us, in public health nutrition work, poverty is multi-dimensional. It relates to powerlessness, to exclusion and thus discrimination, to exploitation, to victimization and to violence. It is also related to migration, to forced displacement, to land-grabbing and corporate environmental degradation, rising urbanization, and to loss of livelihoods. Yet, the SUN Initiative, in its call for nutrition to be placed more at the centre of development, refuses to accept this, with all the implications this carries.

\section{Box 2}

\section{BMGF and its links with the food and beverages industry}

BMGF is also the chief funder of both SUN and GAIN. The Foundation has several links with the food and beverages industry. As of 2014, it had invested in companies like Archer Daniels Midland, Kraft, Mondelez International, Nestle and Unilever, Coca-Cola, and Pepsico (Global Justice Now, 2016). Though the Foundation divested its investment portfolio in McDonald's and Coca-Cola in December 2014, it has invested in Arcos Dorados Holdings, Inc., which is Latin America's largest operator of McDonald's franchises. It also continues to hold stock in Coca Cola FEMSA, the largest bottler of Coca Cola, with a presence in several countries. Gates' partner Warren Buffet, is the single largest investor in Coca-Cola. BMGF's holding in Coca-Cola FEMSA pays the third highest dividend in the Gates portfolio (Intelligent Income, May 2019).

BMGF views under-nourishment as "an exciting opportunity" to "drive a potential publicprivate partnership to deliver this intervention in undernourished populations" of pregnant and lactating women...(T)he designed product(s) could be promoted using a blended or "layered" approach that combines a market-based strategy with public distribution. Similar concepts are being developed and tested for complementary foods and home-fortification products such as micronutrient powder for children aged 6-23 months (BMGF, 2017)." 


\section{Who drives SUN and the global nutrition agenda?}

Corporations typically present themselves as 'private interest working for public good'. They prefer to work through 'partnerships and collaborations.' In the area of nutrition policy and implementation, Hawkes and Buse (2011) note that these words comprise a "mélange of interactions involving a range of different activities, from education campaigns to joint research activities, and a range of processes and structures for interaction". This allows them to use language that has been designed to have different associations for different actors such as 'multistakeholder partnerships' and 'working collaboratively with government, policy-makers, academics and civil society' and thus places them in a position to intervene in policy-making. This also aids them in developing what are essentially self-serving political positions, planting them into proposals that appear to promote social values, while at the same time, attempting to limit government interventions in the market. This allows them to place themselves in global and national nutrition governance systems, where they can appropriate and redefine these values, as well as policy proposals related to public good, so that they achieve their corporate interests.

In the past, the global nutrition agenda was set primarily by the SCN. In early 2009, based on a World Bank initiative, UN entities such as UNICEF, UNDP, the SCN and donors such as the UK and Canada's development agencies, the Bill and Melinda Gates Foundation, Save the ChildrenUSA, Hellen Keller International and others developed the Global Action Plan for Scaling Up Nutrition Investments. This plan created space for the private sector to play an increasingly important role in driving the global nutrition agenda.

Donor agencies have consistently tried to steer SCN's work on nutrition their way. This is why keeping close links to the SCN has been an overarching need for the SUN Initiative; the built-in conflict of interest does not really allow the SCN to take a critical stand on SUN's shortcomings, as is its mission and mandate, especially of SUN's ignoring the human right to nutrition and HRbased approaches and its muddying of the role and actual behaviour of the private sector. In the past, the efforts of some individual civil society SUN members to introduce human rights language were vetoed by the donors backing the Initiative, and up to today, attempts to include human rights concerns in the Roadmap have had little success beyond a token mention of them.

The limited opposition to the corporate takeover of nutrition, as exemplified by SUN, raises concerns about corporations' short- and medium-term impact on local nutrition systems. This includes their capacity to achieve measurable and sustainable results, their disregard of the SDN and of the right to nutrition, as well as their contribution to a fragmented, vertical approach in global nutrition governance.

States are mandated to protect the right to nutrition by adopting measures that reduce the negative public health impacts of the existing food systems. Moreover, States must take immediate measures to make a progressive transition to more sustainable diets. Some WHO recommendations on this have included: using taxation to encourage healthy diets, revising the existing system of subsidies, and regulating marketing practices. 
Much more grassroots activism will also be needed to make sure that global standards are not influenced by corporations trying to assure private profits as they act only purportedly in the public interest. On the positive side, a critical reflection and action on the governance role of global PPPs has emerged. Broadening such an effort has been the guiding principle of the People's Health Movement (www.phmovement.org) and of the International Baby Food Action Network (IBFAN) (www.ibfan.org).

\section{STRATEGIES TO REGAIN CONTROL}

Grassroots organizations and people's movements have identified several strategies for people to regain control over food and nutrition. Here we review just some of the available options presented in no particular order of priority. The list is by no means complete. Many other action points were implied in this article's body and are not repeated here.

- Use a social determinant of nutrition approach and the concept of food sovereignty instead of food security; the SDN and food sovereignty are actually closely related. - Establish links with groups working to oppose TNCs hegemony and join hands with them in rejecting the corporations executives' calls for corporate social responsibility and, instead, based on the principles of human rights, demand and monitor corporate social accountability regarding corporate violations of the SDN.

- In the area of external funding (wrongly called 'foreign aid') for ready-to-use therapeutic foods, identify local food alternatives that can be produced locally by communities themselves..

- Oppose the use of ready to use supplementary foods (RUSF) for the prevention of severe malnutrition; denounce such attempts, proposing SDN-based policies instead.

- Work with lawyers and judges on the legal aspects of the Right to Adequate Food and Nutrition on their use of this right in court.

- Insist on claim holder participation in the design, implementation and monitoring of all development projects/programs.

- Denounce PPPs given their inherent clear conflict of interest and their being considered as a prime policy development model.

- Create a similar long-term watch-dog mechanism as the one used by IBFAN to monitor Big Food and Big Soda.

- Ensure that that policy making on behalf of public health follows the principles of democratic governance. Work towards ensuring that the SUN Initiative, once and for all, handles the issue of conflicts of interest. The reform of SUN also needs to cover human rights principles of accountability, participation, and non-discrimination. Keep pressuring the SUN Initiative to include actions on the SDN and a more decidedly rights-focused approach as its new Roadmap is being rolled out; become a SUN watch-dog.

- Actively participate in the debate of the SDGs global strategy for development; critique the fact that goals are easy to set, but the crucially important processes needed to reach the goals have been neglected. 
- Lobby for the UN Special Rapporteur on the Right to Food position to become a permanent position within the UN system to provide a dedicated and progressive focal point for action.

- Transpose into domestic legislation the International Code of Marketing of Breast-milk Substitutes and the subsequent World Health Assembly (WHA) resolutions on the marketing of breastmilk substitutes and of foods and non-alcoholic beverages to children and ensure that these laws are effectively enforced.

- Impose taxes on soft drinks (sodas), and on ultra-processed foods, in order to subsidize access to fruits and vegetables and educational campaigns on healthy diets.

- Review the existing systems of agricultural subsidies taking into account the public health nutrition impacts of current allocations, and use public procurement schemes for school-feeding programs and for other public institutions to support the provision of locally sourced, nutritious foods, with particular attention to poor producers and consumers.

- Increase support to farmers' markets and urban and peri-urban agriculture, and ensure appropriate infrastructure to link local producers to the urban consumers.

- Reform the SCN (now merged with SUN into UN Nutrition) to ensure its publicinterest agenda and human rights focus are preserved, as well as to make it representative, not only of UN agencies, but also of public interest civil society. The latter's voice must be heard throughout the United Nations system! It is not only about voice, but about influence of claim holders.

- In the sourcing of foods and in nutrition-based interventions, ensure that local food chains are involved and that living wages are paid to workers and fair prices are paid to farmers so as to guarantee the right to nutrition of all people affected-by and involved-in the interventions.

We reiterate: The SUN Team, and claim holders and duty bearers involved in SUN will have to do some hard thinking: Should the SUN Initiative be just 'improved' in its form as a multi-stakeholder initiative with the private sector as a partner, with no conflict of interest safeguards and pretending SUN is 'a movement'? This position should be challenged as a policy. Rather, the call is for its reform in terms of all aspects of its implementation. Recasting the SUN agenda by basing all interventions on the human rights principles of accountability, participation, and non-discrimination, and ensuring that these interventions fit under broader national strategies for the realization of the right to nutrition in order to improve countries' ability to contribute to sustainable, long-term solutions is the call to be made to change the SUN's Roadmap. Such a call, based on a political analysis, is what FIAN, IBFAN and the People's Health Movement are making.

More drastic steps are needed to ensure that nutrition interventions strengthen local people's mobilization and influence, as well as strengthening food systems so as to favour the switch to agro-ecology and sustainable diets. 
In sum, we need to understand that the two challenges presented in this article will only be addressed if all of us, in all corners of the world, recognize that things will not change if we continue with our everyday business as usual. What conclusions you draw from this recognition is up to you. We hope to be able to count on you for what lies ahead.

\section{REFERENCES}

Bes-Rastrollo M, Schulze MB, Ruiz-Canela M, Martinez-Gonzalez MA. 2013. Financial conflicts of interest and reporting bias regarding the association between sugar-sweetened beverages and weight gain: A systematic review of systematic reviews. PLOS Med. 10(12):e1001578. DOI: 10.1371/journal.pmed.1001578

Bill and Melinda Gates Foundation. 2016. Framework and Specifications for the Nutritional Composition of a Food Supplement for Pregnant and Lactating Women (PLW) in Undernourished and Low-Income Settings. Report of an Expert Consultation held at the Bill \& Melinda Gates Foundation on September 19 \& 20, 2016. https://www.securenutrition.org/sites/default/files/resources/attachment/english/BMGF_reportof-an-expert-consultation-held-at-the-bmgf_2017-may.pdf

CDC Foundation. Fiscal year 2018 - Report to contributors. Date unknown [cited 2019 Mar 23]. Available from: https://www.cdcfoundation.org/FY2018/organizations

Coca Cola website. 2019. Our commitment to transparency. https://www.cocacolacompany.com/transparency/our-commitment-transparency

Fanelli D. 2009. How many scientists fabricate and falsify research? a systematic review and meta-analysis of survey data. PLoS ONE. 4(5): e5738.

https://doi.org/10.1371/journal.pone.0005738

Hawkes C, Buse K. 2011. Public health sector and food industry interaction: it’s time to clarify the term 'partnership' and be honest about underlying interests. Eur J Public Health. 21(4):400401. doi:10.1093/eurpub/ckr077

ILSI. Available at https://ilsi.org/

Jessica Fanzo, Yusra Ribhi Shawar, Tara Shyam, Shreya Das, Jeremy Shiffman. 2020. Food System PPPs: Can they advance public health and business goals at the same time? Analysis and ideas for moving forward. GAIN Discussion Paper nr 6. https://www.gainhealth.org/sites/default/files/publications/documents/gain-discussion-paperseries-6-food-systemsy-ppps-can-they-advance-public-health-and-business-goals-at-the-same$\underline{\text { time.pdf }}$

Katzmarzyk PT, Broyles ST, Champagne CM, Chaput JP, Fogelholm M, Hu G, Kuriyan R, Kurpad A, Lambert EV, Maia J, Matsudo V, Olds T, Onywera V, Sarmiento OL, Standage M, Tremblay MS, Tudor-Locke C, Zhao P. 2016. Relationship between soft drink consumption and 
obesity in 9-11 years old children in a multi-national study. Nutrients. 8(12), 770. doi: 10.3390/nu8120770

Mars Centre for Cocoa Health Science. Partnerships. 2017. https://www.marscocoascience.com/research/partnership

O’Connor A. 2015. Coca-Cola Funds Scientists Who Shift Blame for Obesity Away from Bad Diets. New York Times, August 9, 2015 [cited 2019 Mar 23].

https://well.blogs.nytimes.com/2015/08/09/coca-cola-funds-scientists-who-shift-blame-forobesity-away-from-bad-diets/?_r=0

Reddy S, Mazhar S, Lencucha R. 2018. The financial sustainability of the World Health Organization and the political economy of global health governance: a review of funding proposals. Global Health 14, 119. https://doi.org/10.1186/s12992-018-0436-8

Siri-Tarino PW, Qi Sun, Hu FB, Krauss RM. 2010. Meta-analysis of prospective cohort studies evaluating the association of saturated fat with cardiovascular disease. Am J Clin Nutr. 91 (3):535-46.)

SUN brochure. http://scalingupnutrition.org/wp-content/uploads/2016/06/2pager_ENG_20160906_image1.jpg

Yanzhong Huang. 2016. How to Reform the Ailing World Health Organization. https://www.cfr.org/expert-brief/how-reform-ailing-world-health-organization 